\title{
Alcohol consumption, mental health status, and treatment in Nigeria and Uganda
}

\author{
Birgitte Thylstrup, Kim Bloomfield, and Abdu K. Seid \\ Centre for Alcohol and Drug Research, Aarhus University, Aarhus, Denmark
}

\begin{abstract}
Background: The current level of alcohol consumption has placed Nigeria and Uganda in the group of high consumption countries, however little is known about how people with problematic alcohol use and related problems utilize treatment services.
\end{abstract}

Aims: This study examined the relationship between alcohol consumption and mental health status in Nigeria and Uganda, and the relationship between heavy episodic drinking and treatment-seeking and treatment-receiving behavior.

Data and methods: Analyses were based on cross-sectional survey data from Nigeria $(N=2018)$ and Uganda $(N=1478)$ aged $\geq 18$ years from the 2003 Gender, Alcohol, and Culture: An International Study (GENACIS).

Results: In both countries, the level of alcohol consumption was comparatively high, however, associations between drinking status and mental health problems were found only in Nigeria. Heavy episodic drinkers were more likely to report having sought help in both countries, only in Nigeria was it also related to ever receiving help.

Conclusion: National strategies in both countries must continue allocation of resources to treatment services, supporting treatment availability and early identification of alcohol and related mental health problems. Implementation of national alcohol policies should be followed up with assessment and adjustments.

\section{Introduction}

Problematic alcohol consumption entails great human costs for the individual, for the community, and for society in general. It is well established that alcohol use has a causal impact on adverse outcomes, such as somatic diseases (Baliunas, Rehm, Irving, \& Shuper, 2010; Samokhvalov, Irving, Mohapatra, \& Rehm, 2010), social problems (Levola et al., 2013; Rehm et al., 2009), injuries (Taylor et al., 2010; Taylor \& Rehm, 2012), and mental health problems (Grant et al., 2009; Grant et al., 2004).

Studies have shown that the proportion of alcohol consumers who develop alcohol-related and mental health problems increases as the alcohol consumption in a population increases (e.g., Babor, 2003; Caetano \& Cunradi, 2002; Rossow \& Romelsjo, 2006). In consequence, the drinking status in a given population is of great importance from a national public health perspective. Although the level of alcohol consumption on average is lower in Africa compared to European countries, consumption in the form of traditional beverages, spirits, wine, and western lager beer is widely accepted in Nigeria and Uganda (Ibanga, Adetula, Dagona, Karick, \& Ojiji, 2005; Tumwesigye \& Kasirye, 2005). This has placed these countries within the group of high-consumption countries (see for example World Health Organization [WHO], 2004; WHO, 2014). As a result, research on alcohol consumption and related harm have received considerable attention in both Nigeria and Uganda (e.g., Esan, Makanjuola, Oladeji, \& Gureje (2013); Gureje, 1999; Gureje et al., 2007; Kobusingye, Guwatudde, \& Lett, 2001; Obot, 2012; Obot, Wagner, \& Anthony, 2001; Ohaeri \& Odejide, 1993; Ovuga \& Madrama, 2006; Swahn, Palmier, \& Kasirye, 2013; Tumwesigye \& Kasirye, 2005; Tumwesigye, Kyomuhendo, Greenfield, \& Wanyenze, 2012; Tumwesigye, Wanyenze, \& Greenfield, 2012; Zablotska et al., 2009).

Correspondence: Birgitte Thylstrup, Associate Professor, Centre for Alcohol and Drug Research, Aarhus University, Bartholins Allé 10, 8000 Aarhus C, Denmark. Email: bt.crf@psy.au.dk; Telephone: +4587165336; Fax: 87164420

Financial support: Support for certain aspects of this project comes from the WHO; the Quality of Life and Management of Living Resources Programme of the European Commission (Concerted Action QLG4-CT-2001-0196); the U.S. National Institute on Alcohol Abuse and Alcoholism/National Institutes of Health (Grants R21 AA012941 and R01 AA015775); the German Federal Ministry of Health, the Pan American Health Organization; and Swiss national funds. Support for individual country surveys was provided by government agencies and other national sources. The study leaders and funding sources for data sets used in this report are: Nigeria: Akanidomo J. Ibanga, M.Sc., WHO, and Uganda: Nazarius M. Tumwesigye, PhD, WHO. We thank Drs. Ibanga and Tumwesigye, as well as Prof. Isidore Obot, $\mathrm{PhD}, \mathrm{MPH}$, University of Uyo, Uyo, Nigeria, for their kindness in sharing their data with us.

Declaration of interest: The authors declare no conflicts of interest.

Keywords: alcohol, mental health, treatment, Nigeria, Uganda 
Individuals may recover from problematic alcohol consumption without formal treatment, however, in many cases recovery does not take place without relevant help, and seeking this help only happens when the alcohol use and related harms to self and others have become severe (Cunningham \& Breslin, 2004). Considering that identification and access to relevant treatment offers are important for reducing harms related to alcohol consumption (Marlatt \& Witkiewitz, 2002; Room \& Babor, 2005), the current lack of knowledge on associations between alcohol consumption and help-seeking and help-receiving behavior in Nigeria and Uganda is problematic. According to a WHO survey, the annual spending on mental health in 2012 was less than US $\$ 0.25$ per person in low-income countries compared to US \$2 per person on a global level (WHO, 2012). Furthermore, the same research found that $36 \%$ of the people living in low-income countries were covered by mental health services compared to $92 \%$ of the people living in high-income countries. Thus, from a public health perspective, improved knowledge on associations between alcohol consumption and help-seeking and help-receiving behavior in Nigeria and Uganda are important for future equitable and efficient use of available resources within the alcohol and mental health fields in both Nigeria and Uganda.

The aims of this study were to investigate (1) the relationship between alcohol consumption and mental health status (MHS) in Nigeria and Uganda, and (2) the relationship between heavy episodic drinking (HED) and treatmentseeking and treatment-receiving behavior.

\section{Method}

\section{Samples}

The present study was based on data from Gender, Alcohol, and Culture: An International Study (GENACIS) (Bloomfield et al., 2005; Wilsnack, Wilsnack, Kristjanson, Vogentanz-Holm, \& Gmel, 2009). We used data on alcohol consumption, drinking patterns, and alcohol problems for the general population aged 18 and above in Nigeria and Uganda. In Nigeria, the sample was drawn from three states in the north zone and two states in the south zone. Forty of the 60 enumeration areas in each state were chosen randomly, and in housing units with more than one unit, one of the units was selected using a table of random numbers. In Uganda, the sample was drawn from selected districts in the western, central, eastern, and northern regions. Within each district, a mix of sampling techniques was used, including stratification by county followed by simple random sample selection of $50 \%$ of the sub-counties and $25 \%$ of the parishes. Within each parish, one village was randomly selected, and 11 households in the village were selected using systematic sampling (Ibanga et al., 2005). In Nigeria, interviewers were recruited from the Federal Office of Statistics, and in Uganda, interviewers were recruited by the researchers (Tumwesigye \& Kasirye, 2005). In total, 3,496 informants were included; Nigeria $(n=2018,88 \%$ response rate) and Uganda ( $n=1478,84 \%$ response rate).

\section{Measures \\ Drinking status}

Categories for drinking status were defined according to the WHO categories for alcohol consumption (WHO, 2004; Wilsnack et al., 2009): (0) Abstainer (never consumed alcohol in lifetime); (1) Former drinker (previous alcohol use, but not the last 12 months); (2) Current drinker (current alcohol use). These categories were determined by use of a last-12-month drinking frequency question, which identified the last-12-month drinker status. Those who had answered that they had not drunk alcohol in the last 12 months were qualified as current abstainers and were then asked whether they either never had drunk alcohol at all (lifetime abstainer) or whether they had drunk alcohol previously (former drinker). Those who had drunk alcohol within the past 12 months were categorized as current drinkers. Survey respondents who reported to be current drinkers were asked about consumption of five or more drinks in a single day (Wilsnack et al, 2009). From this a dummy variable (1) was used if a respondent reported HED, drinking more than five standard drinks of alcohol (60 or more grams of pure alcohol) in a day.

\section{Mental health status and treatment-seeking behavior}

Self-rated MHS was rated on a five-point Likert scale (poor, fair, good, very good, excellent) based on the question "How has your emotional/mental health been in the last 12 months?" Due to few responses in certain answer categories, the five answer categories were collapsed into three by combining poor and fair into "fair" and very good and excellent into "very good." This approach has been used in many similar studies (e.g., Bora \& Saikia, 2015; Habib, Elzein, \& Hojeij, 2013; Mayer \& Foster, 2015).

As indicator for treatment-seeking behavior, we used three questions from the GENACIS study answered in a yes/no format: 1) "Did you ever consider seeking help for drinking or alcohol-related problems?" In the case of a positive answer, the next question was 2) "Did you ever receive help?" and, if yes: 3) "Did you receive help the last 12 months?" A dummy value of one was coded if the respondent answered affirmative to each question.

\section{Socio-demographic factors}

Six socio-demographic factors were used as covariates: age, gender, employment, civil status, religious affiliation, and education. Age was classified into three categories: 17-29 years, 30-44 years, and 45+ years. Employment was classified as employed, student, unemployed, homemaker, and other. Civil status was classified as single, in relationship (married and co-habitating), and not in relationship (widowed, divorced, and separated). Religious affiliation differed between countries. In Nigeria, religious affiliation was classified as Muslim, Christian, Traditional, and other. In Uganda, the classifications were Muslim, Catholic, Protestant, and other. Education was classified according to the International Standard Classification of Education (UNESCO Institute for Statistics, 1997) and coded as Low $=$ Pre-primary and primary; Middle = 
Low/upper/post-secondary; High = First-/second-stage tertiary).

\section{Analyses}

First, bivariate analyses were run to test associations between all study variables (i.e., socio-demographics, alcohol use, and MHS), as well as help-seeking and helpreceiving behavior. Variables with significant bivariate associations were then included in multivariable regression models to test the relationship between alcohol use and MHS and help-seeking and -receiving behavior. Multinomial modeling was used to test the relationship between alcohol use and MHS. Two multinomial logistic models were examined for each country: fair versus very good MHS, and good versus very good MHS. Finally, we ran a multiple logistic regression model to test the relationship between HED and help-seeking and help-receiving, controlling for MHS. $P$ values for the logistic regression results were adjusted using the Šidák correction method to compensate for a possible increased risk of committing Type-I errors. The Hosmer-Lemeshow test was used to assess the fit of the logistic regression models. $P$ values for all results are twotailed with an alpha level of .05 as cut-off level. All analyses were conducted with the available data on each variable; in other words, we dealt with the issue of missing values through list-wise deletion. All the analyses were conducted using Stata 14.

\section{Results}

\section{Descriptive statistics}

Participant characteristics are shown in Table 1. There were significant differences between Nigeria and Uganda in all areas except employment and HED. Nigeria had more male respondents and Uganda more female respondents, more respondents in Nigeria were over 45 years of age and fewer were between 17-29 years of age compared to Uganda. In Nigeria, more respondents had a higher education and were currently in a relationship. In both countries, nearly all reported a religious affiliation, with most respondents in Nigeria reporting Christian affiliation, and a similar proportion in Uganda reporting either Catholic or Protestant affiliation. As for MHS, the majority of respondents in
Nigeria reported a very good MHS compared to Uganda, where most reported a good MHS. As for drinking status, more reported being abstainers in Nigeria and more reported being current drinkers in Uganda. In both countries, about $60 \%$ were employed, $10 \%$ were students, and $4 \%$ were unemployed, with a sixth to a fifth of the sample being homemakers. There was no significant difference in HED between the two countries.

\section{Associations between alcohol consumption and mental health}

Table 2 reports the results of the multinomial logistic regression models that examined the relationships between drinking status and reported MHS in each country (model 1), and HED and reported MHS (model 2), controlling for socioeconomic and demographic factors in both models. We used very good MHS as the reference category. Regarding model 1, we found no relationship between drinking status and MHS in Uganda. However, in Nigeria, current drinkers compared to abstainers had decreased odds of reporting fair MHS compared to very good MHS, and former drinkers compared to abstainers had lower odds of reporting good MHS compared to very good MHS. With regard to model 2, we only found significant associations in Nigeria; respondents who reported HED were more likely to report a less good MHS compared to respondents who did not report HED.

\section{Associations between treatment-seeking and -receiving behavior and heavy episodic drinking}

Table 3 report the results of the logistic regression model that investigates the relationship of treatment-seeking behavior on HED, using treatment-seeking and -receiving behavior as three separate outcome variables and controlling for MHS in addition to sociodemographic covariates.

In Nigeria, HED was positively related to help-seeking and ever receiving help, and both good and very good MHS were protective for all three help-seeking/-receiving variables. In Uganda, HED was significantly and positively related only to seeking help for alcohol-related problems; good and very good MHS were protective against seeking help; and good mental health was protective for ever having received help.

Table 1

Characteristics of the study samples and statistical comparisons between countries (\%)

\begin{tabular}{|c|c|c|c|}
\hline & Nigeria $(n=2018)$ & Uganda $(n=1478)$ & $p$ value* \\
\hline Gender & & & .024 \\
\hline Male & 53.2 & 48.7 & \\
\hline Female & 46.8 & 51.3 & \\
\hline Age & & & $<.001$ \\
\hline $17-29^{\mathrm{a}}$ & 29.5 & 46.8 & \\
\hline $30-44$ & 39.6 & 37.6 & \\
\hline $45+$ & 30.8 & 15.6 & \\
\hline Education & & & $<.001$ \\
\hline Low & 37.1 & 46.4 & \\
\hline Middle & 53.0 & 47.7 & \\
\hline High & 9.9 & 5.9 & \\
\hline Employment & & & .465 \\
\hline
\end{tabular}




\begin{tabular}{|c|c|c|c|}
\hline & Nigeria $(n=2018)$ & Uganda $(n=1478)$ & $p$ value* \\
\hline Employed & 62.0 & 61.1 & \\
\hline Student & 9.3 & 11.3 & \\
\hline Unemployed & 4.3 & 4.3 & \\
\hline Homemaker & 15.0 & 20.3 & \\
\hline Other & 9.4 & 3.0 & \\
\hline Marital status & & & $<.001$ \\
\hline Single & 18.2 & 28.7 & \\
\hline In relationship & 73.0 & 59.4 & \\
\hline Not in relationship ${ }^{\mathrm{b}}$ & 8.8 & 11.9 & \\
\hline Religion & & & $<.001$ \\
\hline Muslim & 14.2 & 9.9 & \\
\hline Christian & 83.8 & $\mathrm{n} / \mathrm{a}$ & \\
\hline Catholic & $\mathrm{n} / \mathrm{a}$ & 50.3 & \\
\hline Protestant & $\mathrm{n} / \mathrm{a}$ & 34.8 & \\
\hline Traditional & 1.6 & $\mathrm{n} / \mathrm{a}$ & \\
\hline Other & 0.4 & 5.0 & \\
\hline Mental Health Status & & & $<.001$ \\
\hline Fair & 19.4 & 25.5 & \\
\hline Good & 28.1 & 40.5 & \\
\hline Very good & 52.5 & 34.0 & \\
\hline Drinking Status & & & $<.001$ \\
\hline Current drinkers & 33.0 & 47.0 & \\
\hline Former drinkers & 18.9 & 20.4 & \\
\hline Abstainers & 48.1 & 32.6 & \\
\hline Heavy Episodic Drinking & 17.3 & 16.3 & .402 \\
\hline
\end{tabular}

*Kruskal-Wallis rank test of covariates between countries. n/a =not applicable, i.e., the category was not asked.

${ }^{\mathrm{a}} \mathrm{Age}$ range for youngest group in Uganda $=18-29$ years; ${ }^{\mathrm{b}}$ Includes both divorced and separated respondents; ${ }^{\mathrm{c}}$ Heavy episodic drinking is a separate variable.

Table 2

Multinomial logistic regression examining the relationship between alcohol use and mental health status in Nigeria and Uganda

\begin{tabular}{|c|c|c|c|c|c|c|c|c|}
\hline & \multicolumn{4}{|c|}{ Nigeria } & \multirow{2}{*}{\multicolumn{4}{|c|}{$\begin{array}{c}\text { Uganda } \\
\text { Mental Health Status }\end{array}$}} \\
\hline & \multicolumn{4}{|c|}{ Mental Health Status } & & & & \\
\hline & \multicolumn{2}{|c|}{ Fair vs. very good } & \multicolumn{2}{|c|}{ Good vs. very good } & \multicolumn{2}{|c|}{ Fair vs. very good } & \multicolumn{2}{|c|}{ Good vs. very good } \\
\hline & OR & $95 \% \mathrm{CI}$ & OR & $95 \% \mathrm{CI}$ & OR & $95 \% \mathrm{CI}$ & OR & $95 \% \mathrm{CI}$ \\
\hline \multicolumn{9}{|l|}{ Model 1} \\
\hline \multicolumn{9}{|c|}{ Drinking status (abstainer $=$ ref) } \\
\hline Former & 0.80 & $(0.58-1.11)$ & $0.58 * *$ & $(0.41-0.81)$ & 1.38 & $(0.89-2.15)$ & 1.04 & $(0.71-1.51)$ \\
\hline Current & $0.48 * * *$ & $(0.35-0.66)$ & 1.04 & $(0.80-1.35)$ & 1.14 & $(0.78-1.67)$ & 1.21 & $(0.89-1.66)$ \\
\hline Brant test (chi-square) & $67.02 * * *$ & & & & 12.60 & & & \\
\hline Pseudo $\mathrm{R}^{2}$ & 0.05 & & & & 0.06 & & & \\
\hline$n$ & 1904 & & & & 1371 & & & \\
\hline \multicolumn{9}{|l|}{ Model 2} \\
\hline Heavy Episodic Drinking & 0.80 & $(0.56-1.14)$ & $1.73 * * *$ & $(1.30-2.30)$ & 1.00 & $(0.66-1.52)$ & 1.00 & $(0.70-1.43)$ \\
\hline Brant test (Chi-Square) & $56.34 * * *$ & & & & 11.43 & & & \\
\hline Pseudo $\mathrm{R}^{2}$ & 0.05 & & & & 0.06 & & & \\
\hline$n$ & 1904 & & & & 1333 & & & \\
\hline
\end{tabular}

In the multinomial regression model, very good is used as the reference category.

Two separate models were run for drinking status and heavy episodic drinking predictors.

Covariates included in regression models: gender, age, education, employment, religion, and civil status.

$* p<.05 ; * * p<.01 ; * * * p<.001$ 
Table 3

Logistic regression models regressing treatment seeking behavior on Heavy Episodic Drinking and Mental Health Status

\begin{tabular}{|c|c|c|c|c|c|c|}
\hline & \multicolumn{3}{|c|}{ Nigeria } & \multicolumn{3}{|c|}{ Uganda } \\
\hline & $\begin{array}{c}\text { Ever sought } \\
\text { help }\end{array}$ & $\begin{array}{c}\text { Ever received } \\
\text { help }\end{array}$ & $\begin{array}{c}\text { Received help } \\
\text { (last } 12 \\
\text { months) }\end{array}$ & $\begin{array}{c}\text { Ever sought } \\
\text { help }\end{array}$ & $\begin{array}{c}\text { Ever received } \\
\text { help }\end{array}$ & $\begin{array}{r}\text { Received } \\
\text { help (last } \\
12 \text { months) }\end{array}$ \\
\hline $\begin{array}{l}\text { Heavy Episodic } \\
\text { Drinking } \\
\text { Mental Health Status }\end{array}$ & $\begin{array}{c}2.93 \\
{[1.91-4.49]^{* * *}}\end{array}$ & $\begin{array}{c}2.14 \\
{[1.14-4.02]^{*}}\end{array}$ & $\begin{array}{c}1.59 \\
{[0.75-3.37]}\end{array}$ & $\begin{array}{c}2.62 \\
{[1.60-4.27]^{* * *}}\end{array}$ & $\begin{array}{c}1.52 \\
{[0.78-2.95]}\end{array}$ & $\begin{array}{c}1.20 \\
{[0.53-2.71]}\end{array}$ \\
\hline $\begin{array}{l}\text { Fair (reference) } \\
\text { Good } \\
\text { Very good }\end{array}$ & $\begin{array}{c}0.27 \\
{[0.17-041]^{* * * *}} \\
0.12 \\
{[0.08-0.19]^{* * *}}\end{array}$ & $\begin{array}{c}0.08 \\
{[0.03-0.16]^{* * *} *} \\
0.06 \\
{[0.03-0.11]^{* * *}}\end{array}$ & $\begin{array}{c}0.05 \\
{[0.02-0.14]^{* * *}} \\
0.04 \\
{[0.02-0.10]^{* * *}}\end{array}$ & $\begin{array}{c}0.50 \\
{[0.29-0.84]^{*}} \\
0.38 \\
{[0.21-0.69]^{* *}}\end{array}$ & $\begin{array}{c}0.50 \\
{[0.25-0.99]^{*}} \\
0.50 \\
{[0.24-1.05]}\end{array}$ & $\begin{array}{c}0.70 \\
{[0.31-1.58]} \\
0.56 \\
{[0.23-1.37]}\end{array}$ \\
\hline Pseudo $\mathrm{R}^{2}$ & 0.13 & 0.21 & 0.25 & 0.09 & 0.05 & 0.04 \\
\hline$n$ & 1862 & 1862 & 1862 & 1195 & 1195 & 1195 \\
\hline
\end{tabular}

Samples based on those who responded to questions on seeking and receiving help. Three separate regressions were run with seeking help, received help, and received help in the last 12 months as outcome variables.

Control variables: gender, age, age-squared, education, employment, religion, and civil status.

Šidák correction was used to adjust $p$ values.

$* p<.05 ; * * p<.01 ; * * * p<.001$

\section{Discussion}

The present paper studied the relationships between drinking status, MHS, and help-seeking and -receiving behavior in general population samples of Nigeria and Uganda. According to our multivariate analyses, current and former drinkers in Nigeria had a lower likelihood of reporting poorer mental health (vs. very good mental health) compared to abstainers. We also found that current drinkers who reported HED were more likely to report a good compared to a very good MHS compared to respondents who did not report HED. These findings in Nigeria confirm what is well known about abstainers in general; that is, that they often report poorer health than drinkers, even after accounting for former drinkers in the analyses (Liang \& Chikritzhs, 2013).

On the other hand, we found no relationship between drinking status and MHS in Uganda. We have no explanations for why these associations for Uganda were not as strong in this study compared to earlier studies. It is likely that some of the differences may be due to cultural and economic changes over the last decades (Anderson, Chisholm, \& Fuhr, 2009), and to possible differences in the respondents' own perceptions and interpretations of the survey questions. Also, surveys may underestimate actual drinking behaviors and MHS due to social desirability and fear of stigma (Henderson, Evans-Lacko, Flach, \& Thornicroft, 2012; Stockwell et al., 2004). Furthermore, the Ugandan sample was smaller than that for Nigeria, which could have led to finding fewer significant associations.

As for help-seeking and -receiving behavior, we found that HED was positively related to help-seeking and ever receiving help in Nigeria, but only positively related to seeking help for alcohol-related problems in Uganda. The fact that heavy episodic drinkers were more likely to report having sought help in both countries indicates that people who engage in risky drinking may experience enough harm to motivate them to seek help. Considering the high prevalence of HED in both Nigeria and Uganda, this is a positive finding, insofar as it shows that help-seeking behavior is taking place in both countries despite possible fear of stigma (Schomerus et al., 2011; Yap, Reavley, \& Jorm, 2013). Still, our findings on help-receiving behavior show that there is room for improvement in service utilization, especially in Uganda. While the associations between HED and help-receiving behavior in Nigeria indicate that the people who suffer alcohol-related consequences are offered help when they seek it, we found no such associations between HED and help-receiving behavior in Uganda.

Our finding on good and very good MHS being negatively associated with seeking help for drinking or alcohol-related problems in both countries is in line with other research findings regarding associations between level of mental health and seeking help for problematic alcohol use (e.g., Blanco et al., 2015). Taking the high prevalence of current and heavy episodic drinkers in both countries into account, this finding underlines the need to continue the identification of problematic alcohol consumption and related harms to self and others, especially in Uganda, where the prevalence of youth drinkers is nearly $50 \%$.

An important part of a national alcohol strategy is to strengthen the availability of early prevention programs and allocate resources to relevant treatment services (Archimi \& Kuntsche, 2014; Marlatt \& Witkiewitz, 2002). For example, studies have shown that workplace programs have the potential to support change in drinking norms and reduction of harmful drinking (e.g., Webb, Shakeshaft, Sanson-Fisher, \& Havard, 2009), and that even brief interventions for harmful alcohol consumption have the potential to reduce alcohol intake (Kaner et al., 2007; Vasilaki, Hosier, \& Cox, 2006). As a part of this strategy, special attention needs to be paid to treatment barriers that have been described in many other studies, such as concerns about privacy, social 
stigma, and lack of social support systems (e.g., Grella \& Stein, 2013; Schomerus et al., 2011; Schmidt \& Room, 1999; Yap et al., 2013). Furthermore, special attention needs to be paid to the consequences of treatment costs and lack of availability of relevant treatment options (Chen et al., 2013; Kaufmann, Chen, Crum, \& Mojtabai, 2013). Uganda in particular experiences a paucity of treatment services and treatment programs that target adults with individual needs (e.g., Abbo, Okello, Muhwezi, Akello, \& Ovuga, 2016).

In both Nigeria and Uganda, there is a strong focus on the associations between high levels of alcohol consumption and aggressive marketing activities. Several studies have discussed the substantial commercial interests involved in promoting alcohol, calling for stronger national alcohol policy and regulation of sale (e.g., WHO, 2011). Additional studies indicate that other highly cost-effective strategies involve making alcohol more expensive and less available, banning alcohol advertising, and increasing the proportion of alcohol that is taxed in settings with high amounts of unrecorded production and consumption (e.g., Anderson et al., 2009). In Uganda, a new Alcohol Control Bill was drafted in 2016, in which a central aim was to counter the alcohol industry distribution strategy targeting youth between 10-24 years with cheap alcohol that is easy to conceal, leading to high levels of drinking and hindering youths' ability to attend school and to be employed (Kasirye, 2016; Swahn et al., 2013). Such measures are essential for improving national policies and the public health infrastructure in both countries, and should be followed up by quality assessment and necessary adjustments (Anderson et al., 2009).

\section{Limitations}

An important strength of the GENACIS study is the use of centralized data and standardized measures. However, results based on one-point assessments of alcohol consumption should be interpreted with caution, since especially younger and heavier drinkers often alternate between abstention/light drinking and moderate/heavy drinking, which only can be identified by using multiple measurements or retrospective measures (Kerr, Fillmore, \& Bostrom, 2002). The sample sizes for each of our study countries, especially Uganda, were not particularly large, and this could have led to a lack of significant relationships. Future surveys should include more questions on mental health to improve analyses of associations between alcohol consumption and MHS. The challenges of alcohol consumption and related harm in Nigeria and Uganda remain a focus of recent reports (e.g., WHO, 2004; 2014), and the present study may inspire future national strategies targeting alcohol consumption and mental health problems in both countries.

\section{Conclusion}

National strategies in Nigeria and especially in Uganda should continue allocation of resources to alcohol treatment services, supporting treatment availability and early identification and treatment of alcohol and related mental health problems. Successful implementation of national alcohol policies should involve assessment and necessary adjustments.

\section{Acknowledgments}

The data used in this paper are from the project Gender, Alcohol and Culture: An International Study (GENACIS). GENACIS is a collaborative international project affiliated with the Kettil Bruun Society for Social and Epidemiological Research on Alcohol and coordinated by GENACIS partners from the University of North Dakota; Aarhus University; the Alcohol Research Group/Public Health Institute; the Centre for Addiction and Mental Health; the University of Melbourne; and the Research Institute of Addiction Switzerland. We thank Associate Professor Morten Hesse for valuable comments on an earlier draft.

Support for aspects of the project comes from the World Health Organization, the Quality of Life and Management of Living Resources Programme of the European Commission (Concerted Action QLG4-CT-2001-0196), the U.S. National Institute on Alcohol Abuse and Alcoholism/National Institutes of Health (Grants R21 AA012941 and R01 AA015775), the German Federal Ministry of Health, the Pan American Health Organization, and Swiss national funds. Support for individual country surveys was provided by government agencies and other national sources. The study leaders and funding sources for data sets used in this report are: Nigeria: Akanidomo Ibanga, M.Sc., World Health Organization, and Uganda: M. Nazarius Tumwesigye, Ph.D., World Health Organization.

\section{References}

Abbo, C., Okello, E., Muhwezi, W., Akello, G., \& Ovuga, E. (2016). Alcohol, substance use and psychosocial competence of adolescents in selected secondary schools in Uganda: A cross sectional survey. International Neuropsychiatric Disease Journal, 7(2), 25387. doi:10.9734/INDJ/2016/25387

Anderson, P., Chisholm, D., \& Fuhr, D. C. (2009). Effectiveness and cost-effectiveness of policies and programmes to reduce the harm caused by alcohol. Lancet, 373, 2234-2246.

Archimi, A., \& Kuntsche, E. (2014). Do offenders and victims drink for different reasons? Testing mediation of drinking motives in the link between bullying subgroups and alcohol use in adolescence. Addictive Behaviors, 39(3), 713-716. doi:10.1016/j.addbeh. 2013.11.011

Babor, T. (2003). Alcohol: No ordinary commodity Research and public policy. Oxford, England: Oxford University Press.

Baliunas, D., Rehm, J., Irving, H., \& Shuper, P. (2010). Alcohol consumption and risk of incident human immunodeficiency virus infection: A meta-analysis. International Journal of Public Health, 55(3), 159166. doi:10.1007/s00038-009-0095-x

Blanco, C., Iza, M., Rodriguez-Fernández, J. M., BacaGarcia, E., Wang, S., \& Olfson, M. (2015). Probability 
and predictors of treatment-seeking for substance use disorders in the U.S. Drug and Alcohol Dependence, 1(149), 136-144. doi:10.1016/j.drugalcdep.2015.01. 031

Bloomfield, K., Allamani, A., Beck, F., Bergmark, K. H., Csemy, L., Eisenbach-Stangl, I., . . Mendoza, M. R. (2005). Gender, culture and alcohol problems: A multinational study - An EU-Concerted Action (Final report). Berlin, Germany: Institute for Medical Informatics, Biometrics \& Epidemiology, Charité Universitätsmedizin Berlin.

Bora, J. K., \& Saikia, N. (2015). Gender differentials in selfrated health and self-reported disability among adults in India. PLOS One, November 4, 1-14. doi: 10.1371/journal.pone.0141953

Caetano, R., \& Cunradi, C. (2002). Alcohol dependence: A public health perspective. Addiction, 97(6), 633-645.

Chen, L. Y., Crum, R. M., Martins, S. S., Kaufmann, C. N., Strain, E. C., \& Mojtabai, R. (2013). Service use and barriers to mental health care among adults with major depression and comorbid substance dependence. Psychiatric Services, 64(9), 863-870. doi:10.1176/ appi.ps.201200289

Cunningham, J. A., \& Breslin, F. C. (2004). Only one in three people with alcohol abuse or dependence ever seek treatment. Addictive Behaviors, 29(1), 221-223. doi: 10.1016/S0306-4603(03)00077-7

Esan, O., Makanjuola, V., Oladeji, B., \& Gureje, O. (2013). Determinants of transition across the spectrum of alcohol use and misuse in Nigeria. Alcohol, 47(3), 249255. doi: 10.1016/j.alcohol.2012.12.011

Grant, B. F., Goldstein, R. B., Chou, S. P., Huang, B., Stinson, F. S., Dawson, D. A., . . Compton, W. M. (2009). Sociodemographic and psychopathologic predictors of first incidence of DSM-IV substance use, mood and anxiety disorders: Results from the Wave 2 National Epidemiologic Survey on Alcohol and Related Conditions. Molecular Psychiatry, 14(11), 1051-1066. doi: 10.1038/mp.2008.41

Grant, B. F., Stinson, F. S., Dawson, D. A., Chou, S. P., Dufour, M. C., Compton, W., . . Kaplan, K. (2004). Prevalence and co-occurrence of substance use disorders and independent mood and anxiety disorders: Results from the National Epidemiologic Survey on Alcohol and Related Conditions. Archives of General Psychiatry, 61(8), 807-816. doi:10.1001/archpsyc.61.8.807 61/8/807

Grella, C. E., \& Stein, J. A. (2013). Remission from substance dependence: Differences between individuals in a general population longitudinal survey who do and do not seek help. Drug and Alcohol Dependence, 133(1), 146-153. doi:10.1016/j. drugalcdep.2013.05.019

Gureje, O. (1999). Country profile on alcohol in Nigeria. In L. Riley \& M. Marshall (Eds.), Alcohol and public health in 8 developing countries (pp. 95-114). Geneva, Switzerland: World Health Organization.

Gureje, O., Kola, L., Uwakwe, R., Udofia, O., Wakil, A., \& Afolabi, E. (2007). The profile and risks of suicidal behaviours in the Nigerian Survey of Mental Health and Well-Being. Psychological Medicine, 37(6), 821-830. doi: 10.1017/S0033291707000311
Habib, R. R., Elzein, K., \& Hojeij, S. (2013). The association between women's self-rated health and satisfaction with environmental services in an underserved community in Lebanon. Women \& Health, 53(5), 451-467. doi:10.1080/03630242. 2013.806387

Henderson, C., Evans-Lacko, S., Flach, C., \& Thornicroft, G. (2012). Responses to mental health stigma questions: The importance of social desirability and data collection method. Canadian Journal of Psychiatry, 57(3), 152-160.

Ibanga, A. K., Adetula, A. V., Dagona, Z., Karick, H., \& Ojiji, O. (2005). The contexts of alcohol consumption by men and women in Nigeria. In I. S. Obot, \& R. Room (Eds.), Alcohol, gender and drinking problems: Perspectives from low and middle income countries (pp. 143-166). Geneva, Switzerland: World Health Organization.

Kaner, E. F., Beyer, F., Dickinson, H. O., Pienaar, E., Campbell, F., Schlesinger, C., . . Burnand, B. (2007). Effectiveness of brief alcohol interventions in primary care populations. Cochrane Database Systematic Review, 2, CD004148. doi:10.1002/14651858. CD004148.pub3

Kasirye, R. (2016, September 26). Historic moment for alcohol control. Retrieved from http://iogt.org/blog/ 2016/09/26/uganda-new-alcohol-control-bill-2016/

Kaufmann, C. N., Chen, L. Y., Crum, R. M., \& Mojtabai, R. (2013). Treatment seeking and barriers to treatment for alcohol use in persons with alcohol use disorders and comorbid mood or anxiety disorders. Social Psychiatry and Psychiatric Epidemiology, 49(9), 1489-1499. doi:10.1007/s00127-013-0740-9

Kerr, W. C., Fillmore, K. M., \& Bostrom, A. (2002). Stability of alcohol consumption over time: Evidence from three longitudinal surveys from the United States. Journal of Studies on Alcohol, 63(3), 325-333.

Kobusingye, O., Guwatudde, D., \& Lett, R. (2001). Injury patterns in rural and urban Uganda. Injury Prevention, $7(1), 46-50$.

Levola, J., Kaskela, T., Holopainen, A., Sabariego, C., Tourunen, J., Cieza, A., \& Pitkanen, T. (2013). Psychosocial difficulties in alcohol dependence: A systematic review of activity limitations and participation restrictions. Disability and Rehabilitation, 36(15), 1227-1239. doi:10.3109/ 09638288.2013 .837104

Liang, W., \& Chikritzhs, T. (2013). The association between alcohol exposure and self-reported health status: The effect of separating former and current drinkers. PLoS ONE, 8(2), e55881. doi:10.1371/journal.pone.0055881

Marlatt, G. A., \& Witkiewitz, K. (2002). Harm reduction approaches to alcohol use: Health promotion, prevention, and treatment. Addictive Behaviors, 27(6), 867-886.

Mayer, A., \& Foster, M. (2015). Understanding recession and self-rated health with the partial proportional odds model: An analysis of 26 countries. PLOS ONE, October 29, 1-19. doi: 10.1371/journal.pone.0140724

Obot, I. S. (2012). Developing countries ignore drinking and driving problems at their own peril. Addiction, 107(7), 1209-1210. doi:10.1111/j.1360-0443.2012. 03834.x 
Obot, I. S., Wagner, F. A., \& Anthony, J. C. (2001). Early onset and recent drug use among children of parents with alcohol problems: Data from a national epidemiologic survey. Drug and Alcohol Dependence, 65(1), 1-8. doi: 10.1016/S0376-8716(00)00239-8

Ohaeri, J. V., \& Odejide, A. O. (1993). Admission for drug and alcohol related problems in Nigeria psychiatric health care facilities in one year. African Journal of Psychiatry, 1(1), 69-74.

Ovuga, E., \& Madrama, C. (2006). Burden of alcohol use in the Uganda Police in Kampala District. African Health Science, 6(1), 4-20.

Rehm, J., Mathers, C., Popova, S., Thavorncharoensap, M., Teerawattananon, Y., \& Patra, J.

(2009). Global burden of disease and injury and economic cost attributable to alcohol use and alcohol-use disorders. Lancet, 373, 2223-2233.

Room, R., \& Babor, T. F. (2005). World Health Organization's global action on alcohol: Resources required to match the rhetoric. Addiction, 100(5), 579 580. doi:10.1111/j.1360-0443.2005.01101.x

Rossow, I., \& Romelsjo, A. (2006). The extent of the 'prevention paradox' in alcohol problems as a function of population drinking patterns. Addiction, 101(1), 8490. doi:10.1111/j.1360-0443.2005.01294.x

Samokhvalov, A. V., Irving, H., Mohapatra, S., \& Rehm, J. (2010). Alcohol consumption, unprovoked seizures, and epilepsy: A systematic review and meta-analysis. Epilepsia, 51(7), 1177-1184. doi: 10.1111/j.15281167.2009.02426.x

Schmidt, L., \& Room, R. (1999). Cross-cultural applicability in international classifications and research on alcohol dependence. Journal of Studies on Alcohol, 60(4), 448462.

Schomerus, G., Lucht, M., Holzinger, A., Matschinger, H., Carta, M. G., \& Angermeyer, M. C. (2011). The stigma of alcohol dependence compared with other mental disorders: A review of population studies. Alcohol, 46(2), 105-112. doi:10.1093/alcalc/agq089

Stockwell, T., Donath, S., Cooper-Stanbury, M., Chikritzhs, T., Catalano, P., \& Mateo, C. (2004). Under-reporting of alcohol consumption in household surveys: A comparison of quantity-frequency, graduatedfrequency and recent recall. Addiction, 99(8), 1024 1033. doi:10.1111/j.1360-0443.2004.00815.xADD815

Swahn, M. H., Palmier, J. B., \& Kasirye, R. (2013). Alcohol exposures, alcohol marketing, and their associations with problem drinking and drunkenness among youth living in the slums of Kampala, Uganda. ISRN Public Health, 1-9. doi:10.1155/2013/948675

Taylor, B., Irving, H. M., Kanteres, F., Room, R., Borges, G., Cherpitel, C., . . Rehm, J. (2010). The more you drink, the harder you fall: A systematic review and meta-analysis of how acute alcohol consumption and injury or collision risk increase together. Drug and Alcohol Dependence, 110(1-2), 108-116. doi: 10.1016/j.drugalcdep.2010.02.011

Taylor, B., \& Rehm, J. (2012). The relationship between alcohol consumption and fatal motor vehicle injury: High risk at low alcohol levels. Alcoholism: Clinical and Experimental Research, 36(10), 1827-1834. doi:10.1111/j.1530-0277.2012.01785.x
Tumwesigye, N. M., \& Kasirye, T. (2005). Gender and the major consequences of alcohol consumption in Uganda. In I. S. Obot \& R. Room (Eds.), Alcohol, gender and drinking problems - Perspectives from low and middle income countries. Geneva, Switzerland: World Health Organization.

Tumwesigye, N. M., Kyomuhendo, G. B., Greenfield, T. K., \& Wanyenze, R. K. (2012). Problem drinking and physical intimate partner violence against women: Evidence from a national survey in Uganda. $B M C$ Public Health, 12, 399. doi: 10.1186/1471-2458-12399

Tumwesigye, N. M., Wanyenze, R. K., \& Greenfield, T. K. (2012). Intoxication before last sexual intercourse and HIV risk behavior among men and women in Uganda: Evidence from a nationwide survey. International Journal of Alcohol and Drug Research, 1(1), 17.

UNESCO Institute for Statistics. International Standard Classification of Education 1997. Montreal: UNESCO; 1997.

Vasilaki, E. I., Hosier, S. G., \& Cox, W. M. (2006). The efficacy of motivational interviewing as a brief intervention for excessive drinking: A meta-analytic review. Alcohol, 41(3), 328-335. doi:10.1093/alcalc/ag1016

Webb, G., Shakeshaft, A., Sanson-Fisher, R., \& Havard, A. (2009). A systematic review of work-place interventions for alcohol-related problems. Addiction, 104, 365-377.

Wilsnack, R. W., Wilsnack, S. C, Kristjanson, A. F., Vogentanz-Holm, N. D., \& Gmel, G. (2009). Gender and alcohol consumption: Patterns from the multinational GENACIS project. Addiction, 104(9), 1487-1500. doi: 10.1111/j.1360-0443.2009.02696.x

World Health Organization. (2004). WHO Global Status Report on Alcohol 2004. Geneva, Switzerland: Department of Mental Health and Substance Abuse.

World Health Organization. (2011). Alcohol marketing practices in Africa: Findings from the Gambia, Ghana, Nigeria, and Uganda. Brazzaville, Republic of the Congo: World Health Organization, Regional Office for Africa.

World Health Organization. (2012). Zero draft global mental health action plan. Geneva, Switzerland: Department of Mental Health and Substance Abuse.

World Health Organization. (2014). Global status report on alcohol and health. Geneva, Switzerland: Department of Mental Health and Substance Abuse.

Yap, M. B., Reavley, N. J., \& Jorm, A. F. (2013). Associations between stigma and help-seeking intentions and beliefs: Findings from an Australian national survey of young people. Psychiatry Research, 210(3), 1154-1160. doi:10.1016/j.psychres.2013. 08.029

Zablotska, I. B., Gray, R. H., Koenig, M. A., Serwadda, D., Nalugoda, F., Kigozi, G., . . . Wawer, M. (2009). Alcohol use, intimate partner violence, sexual coercion and HIV among women aged 15-24 in Rakai, Uganda. AIDS and Behavior, 13(2), 225-233. doi:10.1007/s10461-007-9333-5 